\title{
Uncovering the Relationship of Supply Chain Management and Firm Performance: Evidence from Textile Sector of Pakistan
}

\author{
Zahid Hussain ${ }^{1}$, Dr. Ahmad Bin Jusoh², Muhammad Sarfraz ${ }^{3}$, Khalil Ur Rehman Wahla ${ }^{4}$ \\ ${ }^{1}$ Ph.D Scholar, Universiti Teknologi Malaysia \\ ${ }^{2}$ Associate Professor, Faculty of Management, Universiti Teknologi, Malaysia \\ ${ }^{3} \mathrm{Ph} . \mathrm{D}$ Scholar, Universiti Teknologi Malaysia \\ ${ }^{4}$ Ph.D Scholar, Faculty of Management Sciences, International Islamic University, Islamabad \\ zahid_kahlon1@yahoo.com; ahmadj@management.utm.my; sarfraz39572@yahoo.com; \\ khalilwahla@gmail.com
}

\begin{abstract}
The purpose of this research paper was to find the impact of the supply chain on firm performance in Textile firm of Pakistan. Data was collected through questioners in the month of March 2018, Approximately 30 questioners were distributed among the managers of the ten textile organizations in Faisalabad which are expected to have the best knowledge about the supply chain operations and its impact on the performance of the organization, all of them responded positively. It is found that dimensions associated with SCM methods as well as explain the connection amongst SCM methods, aggressive benefit, as well as firm performance. The actual study focuses on the causal associations in between SCM exercise, aggressive benefit as well as firm performance as well as ignores the actual feasible recursive associations.
\end{abstract}

Keywords: Supply Chain Management, Effectiveness, Financial Performance, Organization Performance, Customer Relationship, Level of Information sharing, Postponement, Competitive Advantage.

\section{Introduction}

The efficient management of the supply chain is a very valuable and important way of staying competitive in the market and improving the performance of the organization. It has a very important role to remain competitive as the SCM competes between organizations. In the early 1990's, when world markets got rigorous competition to deliver a product or service in the right place at the right time. Because global organizations have now become competitive in the local market and work should be done to improve the effectiveness of the organization and to improve the supply chain as well as more efficient as to a competitor. Organizations must understand the SC management concepts and practices with a view to increasing competitiveness and profit (Groznik, \& Maslaric, 2010). SCM is defined to achieve the strategic objective of the coordination between the commercial partners and the operations described. The main reason for managing the supply chain on progress in the normal operations of individual organizations and improve the performance of all the steps involved in the supply chain. The objective is to combine more product flow SCM information on the supply chain as a competitive cannons (Feldmann, \& Muller, 2003). Now, many organizations have begun to recognize that there is an important opportunity to build a sustainable and competitive advantage of their global market products and services with a packed client key SCM. The practice and corporate implementation of the strategic suppliers of product quality and the performance of the organizations also have a major impact. Relationship to the provider is important in relation to the type of relevant organizations that are at the cost of improving their business performance.

This study verifies the relationship of the strategic provider in the supply chain to improve product quality and the performance of Pakistani projects. With regard to the washers, this relationship uses a different methodology, such as Pearson correlation regression analysis. The Pakistani manufacturing company has a variety of management programs to improve the value and quality of the product and improve the performance of the organization. Due to globalization, there is intense market competition and companies have to take competitive strategies into their operating systems to stay in the market. Competitive strategies relate to the provision of low-cost products and better quality for the competitor. Strategic competitiveness deals with the latest technology used in its operations to improve product efficiency. To get full advantage, the multinational company must take more productive and more competitiveness. Responsibility is also important in its operation, how fast it satisfies your client, your customer can not wait for your product, if it does not provide it quickly, it will change your company. Manufacturing companies should focus on improving the supply chain management to maximize their output. Most researchers say supply chain 
management (SCM) is essential to survive the world market and get more profitability. At present, most of the organizations focus on their supplier and their clients. It must be aligned between the SCM and the company's strategy. SCM plays a crucial role in creating sustainable benefits for its products and services in the global market.

Some problems occur in the application and understanding of the scope of the practical implementation of the SCM program and to measure the performance problem in team practice and implementation. The combination of all activities is understood by the highest customer satisfaction at low cost. SSP (Strategic Supplier Partnership) is sure to have a positive outcome in the performance of organizations. It has a great impact on the performance of the product and the performance of the organization. It mainly informs us of the relationship between SSP and performance and also has a positive impact on SCM practices. Successful manufacturing companies should emphasize the improvement of the relationship between the SSP in the SCM process. As the supply chain is important in many organizations, it is now considered that buying a business partner's role is increasingly important. Many researchers have shown that they are actively involved in strategic leadership in the organization's planning process. The provider and the internal clients of the organizations play an important role and the production and supply of customers' value outside organizations. The relationship between the internal organization and the promotion of the core function in purchases played a vital role. Their forensic performance function has not yet been studied in the company. Relationship management is now focused on the basis of competitive advantage.

The strategic purchase offers greater development of learning. The basis of company capabilities is that the company is working with a small number of providers and open and secure communications between supplier relations among supply chain members who develop long-term orientation to achieve long-term mutual gains. All of the above capabilities give them the opportunity to maintain a competitive advantage that will allow the company. Some researchers have documented that customer responsiveness is an essential element of any organization to improve competitiveness. Supply chain Management can have a strong emphasis on the overall performance of the organization. In this study, we will examine the impact of all factors in the supply chain that affect the overall performance of organizations; the relationship between customer responsiveness to the supply chain management and the most important overall performance will be examined. In the modern era, organizations are an important part of the ability to make and manage the relationship between the supply chains. Some of the capabilities play a crucial role, such as relationships with the limited number of suppliers and long-term relationships, purchases in the organization's development, but also interventional factors, play a crucial role.

\section{Literature Review}

SCM practices refer to the full set of actions performed in organizations to improve the efficiency of the internal procurement chain. a modern assessment of SCM practices that include the cooperation with the provider, the outsourcing process, time compression cycle, process flow continuity and technological and knowledge exchange, through the quality and relationship of purchase with the client in order to represent the practices of SCM that are part of the empirical study (Alvarado, \& Kotzab, 2001). The use of internal organizational system such as EDI and eliminate excessive inventory of customizations reducing the way to the supply chain. The practice of SCM across the factorial study, the integration of the UK, the exchange of information, the characteristics of service management for supply chain customers, due to the proximity and ability of the JIT relationship long term communication.

Concept SCM: Agreement of vision and purpose of the organization exchange of information, consideration and risk, cooperation, integration of the process, long-term relationships and supply chain leadership. In the review and compilation of the literature process, five different aspects were identified. Strategic association provided with supplier. It is defined as the long-term partnership between the company and the provider. The objective is to achieve long-term benefits in organizational benefit (Hall, 1997). Organizations provide the provider and help the organization in a planning process and solve any problem. It allows the organization to operate efficiently and efficiently with the main provider willing to take responsibility winner or default of the product and services. The provider's participation in product and product design can be profitable. Relationship with client concerns customer complaints and managing quick solutions to their 
problems. This helps the organization have long-term good relations with customers and give more satisfaction, supply chain management: provider performance and performance of company. The component is a very important management of customer relations in this process. The level of information exchange is two main components: the amount of information and the quality of information.

Both of these are more important for SCM practices (Moberg, Cutler, Gross, \& Speh, 2002). How effective information is shared inside and outside the organization. The exchange of communication is a symbol of the SSC relationship. Larchur refers to operations and activities one or more subsequent points of the supply chain. It supports organizations to build flexible supply chains and product development according to customer needs, and product categories and demand functions (Waller, Dabholkar, \& Gentry, 2000). Create a balance between market demand and company capabilities to meet that demand. Competitive advantage is value a company provides to their customer which is other company enable to provide same value. Capabilities of company may give competitive advantage over the competitors (McGinnis, \& Vallopra, 1999). Organizational performance defined as how a company achieving their market goals, and also its overall goals. Increase productivity by using lower cost on inventory management are the short term goals of supply chain management long term goals of supply chain are enhancing profit and its stock supply chain management: Supplier performance and firm performance.

Hypothesis: The framework developed in this SCM proposed that the practices of SCM has and direct impact on the overall performance of the organization and Practices of SCM are supposed to increase the market share of an organization, return made on investment and also help the organization to improve the competitive position in the market (Stanley, \& Wisner, 2001) e.g. strategic partnership with the supplier has resulted an increase in specific benefits in form of overall performance of the organization supply chain management: Supplier performance and firm performance. Relationship with the customer (customer relationship) has shown to increase a prominent improvement in the performance of an organization supply chain management: Supplier performance and firm performance. The level of information sharing, related with lowering the total cost, the rapid and higher rate of fulfilling the orders of the customers, and shortening the time of order cycle (Lin, Huang, \& Lin, 2002). A recent survey had concluded, organizations that are good at SCM, hold advantage of $40 \%-65 \%$ in cash-to-cash cycle time on the other organizations and the top organizations are carrying from 50\%-85\% than their competitors (Fawcett, \& Magnan, 2002).

Hypothesis 1: Firms with the high level of performance of the practices of the SCM will result in the high organization's performance level. Practices of SCM will not only make an impact on the overall performance of the organization, but also on the competitive advantage of the organization. These practices are supposed to improve the organization's competitive advantage using the price/cost, the quality, the delivery dependability, the time to market, and product innovation. Prior studies had identified that some of the components of SCM practices i.e. strategic partnership with the supplier have a major impact on various forms of competitive advantage (i.e. price/cost). For example, the strategic partnership with the supplier will help in improving the supplier performance, and will help to reduce the time to the market (Ragatz, Handfield, \& Scannell, 1997), and will also results in the responsiveness and satisfaction of the customer (Power, Sohal, \& Rahman, 2001). Information sharing will help to high level of integration of supply chain (Fynes, Voss, \& de Burca, 2005) by making enable the organizations for the dependable delivery, also for introducing new product in market quickly. Sharing of information and the quality of information contribute positively towards the satisfaction of the customers and quality of partnership. Strategy for postponement not only helps to increase the flexibility in SCM but also help to balance the global efficiency and responsiveness to the customer.

Hypothesis 2: Firms having active consideration of the practices of SCM will be able to maintain competitive advantage at a high level. Generally competitive advantage suggests, having one or more than one capabilities mentioned below when it is compared with the competitors, low level of prices, high level of quality, high dependability, and shortest time for delivery. Above mentioned capabilities, will in return, will help the organization to improve overall performance (Mentzer, Min, \& Zacharia, 2000). Competitive advantage is a best way for achieving the economic performance at a high level, for achieving customer satisfaction and loyalty, and effectiveness in relationship. The brands having high loyalty will result in less switching rate as compare to their competitors in the target markets and thus increase in sale and profitability (Grover, \& 
Malhotra, 2003). If an organization is providing products with high level of quality can charge extra prices and then is able to increase its profit. An organization with low time to the market will be able to enjoy a huge market share

Hypothesis 3: As the level of competitive advantage will be higher, there will be higher performance of organization.

\section{Methodology}

This section of research describes instrumentation, formulating the models and method used for sampling. Data was collected through questioners in the month of March 2018, Approximately 30 questioners was distributed among the managers of the ten textile firms situated in Faisalabad which are expected to have a best knowledge about the supply chain operations and its impact on the overall performance of the organization, all of them responded positively. Respondents selected to this study were the managers, working on a higher post. The respondents were given a statement either agree or disagree by using a five point Likert scale. Respondents were also asked to refer to their key supplier for the relevant questions. First part is comprised of the (SSP) strategic supplier partnership; describing the impact of the strategic partnership with the supplier of the company, and how they affect the overall performance of the organization, using 5 point Likert scale enabling the respondents to answer the questions. The second part is consisted on the gathering of many performance measurements; (CR) customer relationship; consisted on how the customer is satisfied and up to what extent their complaints are being handled in order to keep the customer loyal to the organization, about meeting the expectations of the customers, as if they are satisfied they how it would affect financially for managing such operations in the organization. (LIS) Level of information sharing, (LIQ) Level of information quality, Postponement, price/cost, Delivery dependability, Product innovation, Time to market, (OP) Organizational performance.

\section{Results}

\begin{tabular}{|c|c|c|c|c|}
\hline \multicolumn{5}{|c|}{ Model Summary } \\
\hline Model & $\begin{array}{l}\mathrm{R} \\
603 \mathrm{a}\end{array}$ & $\begin{array}{l}\text { R Square } \\
363\end{array}$ & $\begin{array}{l}\text { Adjusted R Square } \\
315\end{array}$ & $\begin{array}{l}\text { Std. Error of the Estimate } \\
29124\end{array}$ \\
\hline
\end{tabular}

Predictors: (Constant), Competitive advantage, organizational performance

\begin{tabular}{llllll} 
ANOVA (b) & & & & & \\
\hline Model & Sum of Squares & df & Mean Square & F & Sig. \\
\hline \multirow{2}{*}{$\begin{array}{l}\text { Regression } \\
\text { Residual }\end{array}$} & 1.259 & 2 & .630 & 7.424 & $.003 \mathrm{a}$ \\
$\quad$ & 2.205 & 26 & .085 & & \\
\hline
\end{tabular}

a. Dependent Variable: SCM practices

Predictors: (Constant), competitive advantage, organizational performance

There is a significant correlation between dependent variable supply chain practices and independent variable competitive advantage, organizational performance $(p<0.05)$. It shows the positive correlation among these variable. So this is best fit for regression model. It will also be interesting to note the actual effect of providing a chain framework (the length of the supply chain, the location of the organization within the supply chain, the automotive framework, etc.) on the operation of SCM and aggressive benefits. 


\begin{tabular}{|c|c|c|c|c|c|c|}
\hline \multicolumn{7}{|c|}{$\begin{array}{l}\text { Coefficients (a) } \\
\text { Coefficients }^{\mathrm{a}} \\
\end{array}$} \\
\hline \multirow{2}{*}{ Model } & & \multicolumn{2}{|c|}{ Un standardized Coefficients } & \multirow{2}{*}{$\begin{array}{l}\text { Standardized Coefficients } \\
\text { Beta }\end{array}$} & \multirow{2}{*}{$\mathrm{t}$} & \multirow{2}{*}{ Sig. } \\
\hline & & B & Std. Error & & & \\
\hline \multirow{3}{*}{1} & (Constant) & 1.218 & 0.521 & & 2.338 & 0.027 \\
\hline & $\begin{array}{l}\text { Organizational } \\
\text { Performance }\end{array}$ & 0.138 & 0.138 & 0.188 & 0.997 & 0.328 \\
\hline & $\begin{array}{l}\text { Competitive } \\
\text { Advantage }\end{array}$ & 0.368 & 0.146 & 0.477 & 2.528 & 0.018 \\
\hline
\end{tabular}

a. Dependent Variable: SCM practices

Supply chain practices have no significant correlation with organizational performance. So we reject this hypothesis. Supply chain practices has significant relation with competitive advantage $(p<0.05)$ and accept this hypothesis.

\begin{tabular}{llllll} 
Anova (b) & & & & & \\
\hline Anova $^{\mathbf{a}}$ & & & & & \\
\hline Model & Sum of Squares & df & Mean Square & F & Sig. \\
$\quad$ Regression & 2.171 & 2 & 1.088 & 6.636 & $.005 a$ \\
$1 \quad$ Residual & 4.262 & 26 & .164 & & \\
$\quad$ Total & 6.438 & 28 & & & \\
\hline
\end{tabular}

a. Dependent Variable: Organizational Performance

b. Predictors: (Constant), Competitive Advantage, SCM practices

There is a significant correlation between dependent variable organizational performance and independent variable competitive advantage, supply chain practices $(p<0.05)$. It shows the positive correlation among these variable. So this model is best fit.

\begin{tabular}{|c|c|c|c|c|c|c|}
\hline \multicolumn{7}{|c|}{$\begin{array}{l}\text { Coefficients (a) } \\
\text { Coefficients }^{\mathrm{a}}\end{array}$} \\
\hline \multirow{2}{*}{ Model } & & \multicolumn{2}{|c|}{ Un standardized Coefficients } & \multirow{2}{*}{$\begin{array}{l}\text { Standardized Coefficients } \\
\text { Beta }\end{array}$} & \multirow{2}{*}{$\mathrm{t}$} & \multirow{2}{*}{ Sig. } \\
\hline & & B & Std. Error & & & \\
\hline \multirow{3}{*}{1} & (Constant) & 0.965 & 0.773 & & 1.248 & 0.323 \\
\hline & SCM Practices & 0.267 & 0.268 & 0.196 & 0.997 & 0.328 \\
\hline & $\begin{array}{l}\text { Competitive } \\
\text { Advantage }\end{array}$ & 0.468 & 0.207 & 0.445 & 2.268 & 0.032 \\
\hline
\end{tabular}

a. Dependent Variable: organizational performance

There is no significant correlation between dependent variable organizational performance and independent variable supply chain practices. In such type of organization there is no practice of supply chain. Organization performance has positive correlation with competitive advantage $(\mathrm{p}<0.05)$.

Implication for the Research: The actual study focuses on the causal associations between the practice of SCM, the aggressive benefit and the overall performance of the organization, as well as ignoring the real feasible reactive societies. Improved offensive benefits and the high overall organizational performance can improve the actual amounts of SCM practice. The organization's very high competition can allow a company to apply a higher level related to the SCM practice because it has to constantly violate its competitors and maintain its aggressive location within the powerful business community spot. However, the overall performance of the organization's enhanced organization provides high funds to implement multiple SCM modes. Similarly, overall organizational performance could better enhance real-offensive company benefits. For example, a company can also provide a low cost-paying monetary ability, which provides more than its competitors with price benefits. Since competitors are currently changing between "organizations" in relation 
to "between supply chains", larger companies are accepting more SCM performance within the real desire to reduce supply chain spending and Benefit aggressive. The actual research results help to see the SCM methods that could have a significant impact on the aggressive benefit and the overall performance of the organization. It should be noted that SCM methods can have contextual elements, such as the type of business, the size of the organization, the location of the company within the supply chain, the length of the chain, as well as the type of supply chain. For example, the amount of functioning sentimental customer relations, measured by customer satisfaction and anticipation, maybe more about the company located at the end of the supply chain (close to the customer).

Larger companies may have a greater degree of SCM methods because more generally complex supply chain systems are required that require much more management of the supply chain. Perhaps the length of the supply chain would have a negative impact on the quantity of quality information. The delay and distortion affecting the information, as it moves along the supply chain, is less the actual supply chain, the smallest opportunities you get. In addition, the largest amount of removal may be related to tailor manufacturing techniques compared to manufacturing techniques. As a result of a limited number of results, the actual recharging associated with the buildings was not completed by this investigation. Independent research sets organized collective bans set when the device uses. Long-term research of scales of three-dimensional scales created through this particular research should be validated. Because the idea of a scam is really complicated and the system related to companies is within the work of generating and the final item, your site can not be protected in just 1 research. Long-term research can contribute to the actual position of additional measures to consider considering, for example, close proximity, JIT/ability to read, functional coordination, logistics integration and the supply chain management firm, which is ignored this investigation. The actual long-term study can also verify the relationship/rely on the actual measurements of 5 SCM modes. For example, the actual business of the appropriate supply relationship may need to be addressed on the discussion of information.

The knowledge for this study consists of reactions through solitary participants in a business that may be a trigger for feasible reaction. The results should be interpreted and taking into account this particular restriction. The use of the individual respondent can generate some aspects of accuracy. Long-term research should try to use a number of participants through all their business to improve the results of the study. Similarly, it will be associated with the curiosity that the use of real participants will be used through a series of two-end companies related to the supply chains. By comparing various aspects of SCM methods on supply chain companies, you can identify the power and weakness of the supply chain, as well as the best SCM supply chain practice. Long-term research can study SCM problems at the supply chain level. The solitary chain is solitary, for example, with the curiosity to the characteristics, plan and system that govern this supply chain in particular, the real relationships between individuals within the supply chain (first level providers, the second - service providers, producers, service providers, customers, etc.), as well as the way in which SCM methods change in all participating businesses. The long-term research of the associations that is recommended can be given through contextual parameters to design, for example, the organizational and frame working feature for string work. For example, it is likely that it is interesting to investigate how the SCM exercise changes the business dimension.

\section{Conclusion}

This document provides empirical validation for any construction that identifies 5 key factors related to SCM methods, as well as the link between SCM methods, the aggressive benefits, as well as explaining the overall performance of the organization. This does through the analysis of a research inquiry: (1) the carrying business with larger amounts of aggressive benefits as well as larger amounts of SCM methods; (two) launch business with a higher level related to SCM methods that have larger amounts of total organizational performance; (3) Do businesses have a higher level and higher amounts of the aggressive benefits of the overall performance of the organization? With regard to the purpose of investigating these problems, an extensive, legitimate and reliable device was established in evaluating the SCM methods. The actual device was examined using total record evaluations such as relative validity, discriminatory validity, reliability and the declaration of second-order buildings. This particular study provides empirical evidence to help conceptual and expressive statements within the books about the actual effect of SCM methods. 


\section{References}

Alvarado, U. Y. \& Kotzab, H. (2001). Supply chain management: the integration of logistics in marketing. Industrial Marketing Management, 30(2), 183-198.

Fawcett, S. E. \& Magnan, G. M. (2002). The rhetoric and reality of supply chain integration. International Journal of Physical Distribution \& Logistics Management, 32(5), 339-361.

Feldmann, M. \& Muller, S. (2003). An incentive scheme for true information providing in supply chains. Omega, 31(2), 63-73.

Fynes, B., Voss, C. \& de Burca, S. (2005). The impact of supply chain relationship quality on quality performance. International journal of production economics, 96(3), 339-354.

Grover, V. \& Malhotra, M. K. (2003). Transaction cost framework in operations and supply chain management research: theory and measurement. Journal of operations management, 21(4), 457-473.

Groznik, A. \& Maslaric, M. (2010). Achieving competitive supply chain through business process reengineering: A case from a developing country. African Journal of Business Management, 4(2), 140.

Hall, S. (1997). Representation: Cultural representations and signifying practices (Vol. 2): Sage.

Lin, F. r., Huang, S. h. \& Lin, S. c. (2002). Effects of information sharing on supply chain performance in electronic commerce. IEEE Transactions on engineering management, 49(3), 258-268.

McGinnis, M. A. \& Vallopra, R. M. (1999). Purchasing and supplier involvement: issues and insights regarding new product success. Journal of Supply Chain Management, 35(2), 4-15.

Mentzer, J. T., Min, S. \& Zacharia, Z. G. (2000). The nature of interfirm partnering in supply chain management. Journal of Retailing, 76(4), 549-568.

Moberg, C. R., Cutler, B. D., Gross, A. \& Speh, T. W. (2002). Identifying antecedents of information exchange within supply chains. International Journal of Physical Distribution \& Logistics Management, 32(9), 755-770.

Power, D. J., Sohal, A. S. \& Rahman, S. U. (2001). Critical success factors in the agile supply chain managementAn empirical study. International Journal of Physical Distribution \& Logistics Management, 31(4), 247 265.

Ragatz, G. L., Handfield, R. B. \& Scannell, T. V. (1997). Success factors for integrating suppliers into new product development. Journal of Product Innovation Management, 14(3), 190-202.

Stanley, L. L. \& Wisner, J. D. (2001). Service quality along the supply chain: implications for purchasing. Journal of operations management, 19(3), 287-306.

Waller, M. A., Dabholkar, P. A. \& Gentry, J. J. (2000). Postponement, product customization, and marketoriented supply chain management. Journal of business logistics, 21(2), 133. 